Thorax 1988;43:937-938

\title{
Effect of budesonide on pulmonary hyperinflation in young asthmatic children
}

\author{
A GREENOUGH, J POOL, J G A GLEESON, J F PRICE \\ From the Paediatric Respiratory Laboratory, King's College Hospital, London
}

ABSTRACT In 19 asthmatic children, aged 2-6 years, the effect of six weeks' treatment with inhaled budesonide or placebo on functional residual capacity (FRC-helium dilution) and bronchodilator responsiveness was assessed in a double blind, randomised crossover trial. FRC was increased in most children at the start of treatment. Treatment with budesonide was associated with a reduction in FRC by comparison with placebo (median change $9 \% v 0 \% ; \mathrm{p}<0.05$ ). There was a trend towards a greater response to a bronchodilator after budesonide. The results suggest that inhaled corticosteroids reduce hyperinflation in young asthmatic children.

Measurement of functional residual capacity (FRC) by helium gas dilution is accurate and reproducible in young children.' Most asthmatic children have hyperinflation ${ }^{2}$ and, although this can be reduced acutely by bronchodilator treatment, ${ }^{3}$ though not usually to normal, a pilot study ${ }^{4}$ suggested this hyperinflation may persist for many months. The effect of chronic hyperinflation on lung function is not known but it may be associated with respiratory problems persisting into adulthood. ${ }^{5}$

Budesonide, a topically active corticosteroid, can be delivered by a large volume spacer to young children ${ }^{6}$ and a recent study has shown it to be of clinical benefit to young asthmatic patients.' Our aim was to investigate whether inhaled budesonide influenced hyperinflation and bronchodilator responsiveness, assessed as change in FRC, in young asthmatic children.

\section{Methods}

Budesonide, $200 \mu \mathrm{g}$ twice daily, and placebo were given in random order via a large volume spacing device (Nebuhaler) ${ }^{6}$ for six weeks in a double blind crossover trial, as described elsewhere.' At the beginning and end of each treatment period the children attended the paediatric respiratory laboratory between 8 and $10 \mathrm{am}$. The last dose of budesonide or placebo was administered on the previous evening and inhaled bronchodilator treatment was withheld for at least two hours before pulmonary function testing.

FRC was measured by a helium gas dilution technique, 12 and expressed as the percentage of the volume predicted for

Address for reprint requests: Dr A Greenough, Department of Child Health, King's College Hospital, London SE5 8RX.

Accepted 22 August 1988 height. As the mean coefficient of variation for the measurement of FRC is $4 \%$ we compared the number of children who showed a fall greater than $8 \%$ of that predicted for height. FRC was measured before and 10 minutes after $500 \mu \mathrm{g}$ terbutaline given by Nebuhaler at the beginning and end of each treatment (eight measurements in total) in 19 children. Ten children (five of them boys; mean age 4.4 years) received placebo first and nine (seven of them boys; mean age 4.6 years) budesonide first.

Permission for the study was granted by the King's College Hospital ethics committee and informed consent was obtained from the parents.

FRC measurements were examined for an "order" and "carry over" effect. The number of children who showed a reduction in height predicted FRC of at least $8 \%$ over the treatment period and the number who showed at least $8 \%$ reduction in height predicted FRC in response to bronchodilator treatment were compared by Fisher's exact test. Changes in FRC over the treatment periods were compared by Wilcoxon's rank sum test. Differences in bronchodilator responsiveness after steroid or placebo inhalation were also assessed as changes in FRC by means of the Wilcoxon rank sum test.

\section{Results}

FRC before bronchodilator did not differ significantly at the beginning of the first and second treatment periods: median $129 \%$ (range $51-219 \%$ ) first leg; median $118 \%$ (range 88 $199 \%$ ) second leg. There was no carry over or order effect, so the results from the two legs were analysed together.

More children had FRC values at least $8 \%$ lower after budesonide (13 of 19) than after placebo ( 4 of 19$)(p<0.01)$. There was a greater fall in FRC after budesonide (median change $-9 \%$, range $-90 \%$ to $+33 \%$ ) than after placebo (median change $0 \%$, range $-47 \%$ to $+51 \%$; $<<0.05$ ) (fig). Twelve of 19 children showed a fall in FRC of more than $8 \%$ after terbutaline at the end of each treatment period. Overall, bronchodilator responsiveness tended to be greater after treatment with budesonide (median change in FRC $-6 \%$, range $-47 \%$ to $+31 \%$ ) than after placebo (median range $0 \%$, range $-46 \%$ to $+43 \%$ ), though the difference was not significant. FRC tended to be lower after budesonide (median $112 \%$, range $86 \%-158 \%$ ) than after placebo (median $134 \%$, range $74 \%-164 \%$ ), though the difference was not significant.

\section{Discussion}

Topical corticosteroids are known to be effective in the management of asthma, but little is known of their effect on 


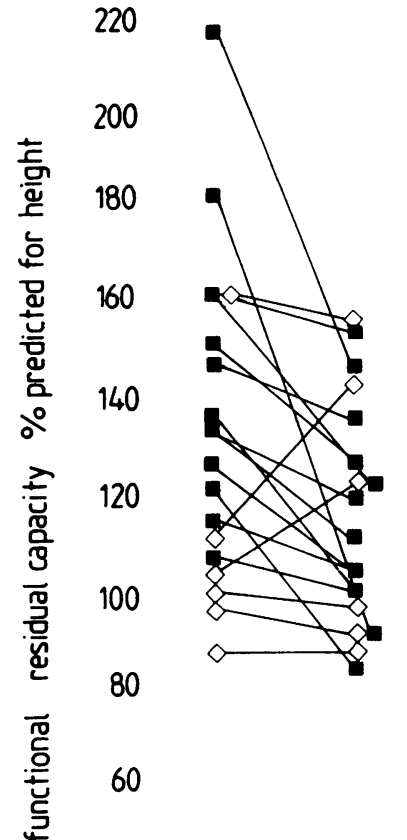

40

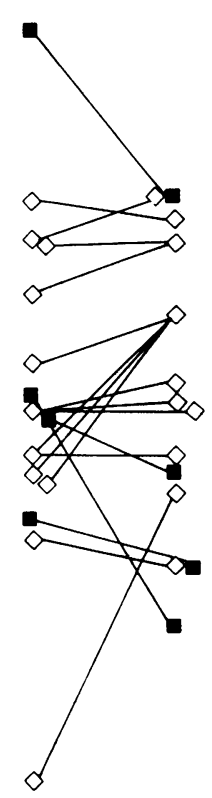

placebo

Change in functional residual capacity $(F R C)$ in individual subjects (expressed as percentages of values predicted for height) after six weeks' budesonide and placebo inhalation. The results for two children receiving placebo overlap. $\square \geqslant 8 \%$ reduction in FRC; $\diamond<8 \%$ reduction in FRC.

lung volume in asthmatic subjects. This study is the first to show a reduction in hyperinflation in young children with

inhaled corticosteroid treatment. Whether these effects persist and whether chronic maintenance treatment with budesonide causes further improvement in respiratory function needs further investigation.

It has been suggested that corticosteroid treatment, though $\frac{\widehat{ }}{\circ}$ predominantly anti-inflammatory, may potentiate the response to a beta agonist. ${ }^{8}$ Although there was a trend to ${ }^{\mathrm{N}}$ improvement in the response to terbutaline this failed to $\vec{\circ}$ reach significance. FRC was reduced by treatment with budesonide, however, and this might have reduced the $\vec{\omega}$ change in FRC in response to a bronchodilator.'

Sister J Pool and Dr J Gleeson are supported by Children Nationwide Medical Research Fund.

\section{References}

1 Greenough A, Stocks J, Nothen U, Helms P. Compliance and functional residual capacity in young children. Pediatr Pulmonol 1986;2:321-6.

2 Greenough A, Pool J, Loftus G, Price J. Abnormalities of lung mechanics in young asthmatic children. Thorax 1987;42:500-5.

3 Greenough A, Loftus BG, Pool J, Price JF. Response to broncho- $\vec{\bullet}$ dilators assessed by lung mechanics. Arch Dis Child 1986;61: 1020-3.

4 Pool JB, Greenough A, Price JF. Abnormalities of functional residual capacity in symptomatic and asymptomatic young asthmatics. Acta Paediatr Scand 1988;77:419-23.

5 Tooley WH, DeMuth G, Nadel JA. The reversibility of obstructive $\overline{\bar{O}}$ changes in severe childhood asthma. J Pediatr 1965;66:517-24.

6 Pool J, Greenough A, Gleeson JGA, Price JF. Inhaled broncho- $\mathbb{D}$ dilator therapy via the nebuhaler in young asthmatics. Arch Dis Child 1988;63:288-91.

7 Gleeson J, Price JF. Controlled trial of budesonide via the 3 nebuhaler in pre-school asthma. $\mathrm{Br}$ Med J 1988;297:163-7.

8 Turner-Warwick MR. Chronic airways obstruction in asthma Asthma Bull 1981;2:3-4.

9 Greenough A, Pool J, Price JF. Assessment of bronchodilator responsiveness in young children by assessment of FRCO [abstract]. Clin Res Physiol 1987;23:407S. 